\title{
Rural and Urban Differences in MDA Coverage for Filariasis in Jharsuguda District of Odisha
}

\author{
Durga Madhab Satapathy ${ }^{1}$, Subrat Kumar Pradhan², Himanshu Prasad Acharya ${ }^{3}$, Udayan Nayak4, \\ Sandeep Kumar Agrawal ${ }^{5}$, Gitismita Naik ${ }^{5}$, Upasana Sinha ${ }^{5}$ \\ 1Professor and Head, ${ }^{2}$ Assistant Professor, ${ }^{3}$ Associate Professor, ${ }^{4}$ Senior Resident, 5 Post Graduate Student, \\ Department of Community Medicine, VIMSAR, Burla, Odisha, India.
}

\begin{abstract}
Background: Filariasis is the common term for a group of diseases caused by parasitic nematodes belonging to super family Filarioidea. Filariasis caused by nematodes that live in the human lymph system is called Lymphatic Filariasis (LF). The infection is prevalent in both urban and rural areas.

Objectives: 1) To assess the coverage of Mass Drug Administration (MDA) for Filariasis (2) To find out the rural and urban difference of MDA coverage

Methods: The study was undertaken as a Post MDA survey with prospective data collection in district of Jharsuguda. The information was collected using a questionnaire developed and based on NVBDCP guidelines. Two rural blocks and two wards of urban area surveyed during February 2016 were selected for this study.

Results: The coverage of MDA in rural area found to be more than urban area. The most common reason for not taking drug in rural area was beneficiary absent at home during drug distribution, where as in urban area the reason was no information about MDA. The percentage of population consuming drugs during MDA was more in rural area than urban area.
\end{abstract}

\section{INTRODUCTION}

Lymphatic Filariasis is the world's second leading cause of longterm disability. It causes debility and imposes severe social and economic burden on the affected individuals, their families and communities. The current estimate reveals that 120 million people in 83 countries of the world are infected with lymphatic filarial parasites and it is estimated that more than 1.1 billion $(20 \%$ of the world's population) are at risk of acquiring infection. Over 40 million people are severely disfigured and disabled by filariasis and 76 million are apparently normal but have hidden internal damage to lymphatic and renal systems. ${ }^{1}$

According to the World Health Organization, India, Indonesia, Nigeria and Bangladesh alone contribute about $70 \%$ of the infection worldwide. ${ }^{2}$ It has been estimated that approximately 5 million Disability Adjusted Life Years (DALYs) are lost annually, ranking third among the Tropical Disease Research (TDR) diseases in terms of DALYs after malaria and TB.
Conclusion: The coverage in rural areas is more than urban areas. This requires the use of mass media such as local TV channels, newspapers, posters and banners at public places for increasing the awareness and coverage of MDA in the urban areas.

Keywords: Lymphatic Filariasis, MDA, NVBDCP.

\section{*Correspondence to:}

Prof Durga Madhab Satapathy

Professor \& HOD

Department of Community Medicine, VIMSAR Burla, Sambalpur, Odisha.

\section{Article History:}

Received: 30-06-2016, Revised: 03-08-2016, Accepted: 08-08-2016

\begin{tabular}{|l|c|}
\hline \multicolumn{2}{|c|}{ Access this article online } \\
\hline Website: & Quick Response code \\
www.ijmrp.com & \\
\hline DOI: & \\
10.21276/ijmrp.2016.2.5.014 & \\
\hline
\end{tabular}

Lymphatic filariasis is a major impediment to socioeconomic development and also a major cause and effect of poverty. The discovery of microfilaria $(\mathrm{mf})$ in the peripheral blood was made first by Lewis in 1872 in Kolkata City. ${ }^{1}$

Indigenous Lymphatic Filariasis cases are reported from 20 States/UTs namely Andhra Pradesh, Assam, Bihar, Chhattisgarh, Goa, Gujarat, Jharkhand, Karnataka, Kerala, Madhya Pradesh, Maharashtra, Orissa, Tamil Nadu, Uttar Pradesh, West Bengal, Pondicherry, Andaman \& Nicobar Islands, Daman\& Diu, Lakshadweep and Dadra \& Nagar Haveli. From these States/UTs, a total of 250 districts have been identified to be endemic for filariasis with a population of about 600 million at risk. ${ }^{3}$ Morbidity surveys (up to 2012) of filarial cases in the states/UTs revealed 8 lacs cases of lymphedema and 4 lacs cases of hydrocele. ${ }^{3}$ The microfilaria survey reports received from 205 districts revealed microfilaria rate of about $0.45 \% .{ }^{4}$ Nearly 2.5 crore population of Odisha living in 20 endemic districts are at risk with 5 to 10 per 
cent of them suffering from various manifestations of the disease. As per available data, 79,912 persons in the State are recorded to be suffering from lymphedema and 37,085 from hydrocele. ${ }^{3}$

WHO launched its Global Programme to Eliminate Lymphatic Filariasis (GPELF) in 2000 with the aim of eliminating the disease as a public health problem. In 2012, the WHO NTD Roadmap reconfirmed the target date for achieving elimination as 2020.4 The Government of India is signatory to the World Health Assembly Resolution in 1997 for Global Elimination of Lymphatic Filariasis. The National Health Policy (2002) envisages elimination of lymphatic filariasis in India by 2015. Annual Mass Drug Administration (MDA) of single dose of DEC (Diethylcarbamazine citrate) and Albendazole for 5 years or more to the eligible population (except pregnant women, children below 2 years of age and seriously ill persons) to interrupt transmission of the disease. Home based management of lymphedema cases and up-scaling of hydrocele operations in identified CHCs/ District hospitals /medical colleges. DEC tablets are available with health workers or volunteers during MDA who make house to house visits and give tablets. Drug distribution booth is also set up at health facilities and other public places during MDA campaign. These tablets are supplied free. Adult female filaria worm lives in body usually for 5-7 years \& produce microfilaria, therefore the MDA is implemented for 5-7 years. The transmission can be eliminated after 5 to 7 round of MDA covering a minimum of $85 \%$ population.

MDA is being implemented in India since year 2004. In 2007 India changed its strategy from delivery of DEC alone to delivery of DEC plus Albendazole; the number of people treated with combinations has increased steadily. India has reduced the prevalence to less than $1 \%$ in 192 out of 250 districts. In implementation units in Nalgonda in Andhra Pradesh, the prevalence of microfilaria was reduced from $17 \%$ (2004) to $0.8 \%$ in 2009.4 Odisha has reported an MF rate of 0.43 in 2011 compared to 2.57 in 2004 . However, coastal districts are more endemic for the disease, particularly the district Puri. MDA assessment is being held in Odisha every year since 2004. Till 2014 coverage was more than $85 \%$, except for 2012 when the survey was not done. ${ }^{5}$ With this background the study was conducted in Jharsuguda district to determine the coverage of Mass Drug Administration (MDA) for Filariasis and to find out the rural and urban difference of MDA coverage.

\section{METHODS}

The assessment of post-MDA activity of Jharsuguda district for 2015 was carried out by the Department of Community Medicine, VSS Medical College, Burla in February 2016.Of total five blocks, two blocks viz. Kolabira \& Lakhanpur for rural coverage and 2 wards viz. ward no 14 and 16 from Jharsuguda town were randomly selected for urban coverage of MDA for Jharsuguda district. From each block, two sub centers were selected randomly, and from each sub-centre five villages were selected. The survey started with a visit to the block $\mathrm{CHC}$ where a rough map was prepared to visit the respective villages in the two blocks. In each village ten households were selected randomly for data collection.

In total 300 households were surveyed of which 200 from rural area and 100 from urban area. The data were collected from each household on the day of the survey in the pre-designed format for data collection. From each household an adult respondent was sought among those present at the time of the survey. Informed verbal consent was taken from the respondent following introduction and information regarding the purpose of the survey. Detailed data were collected in the prescribed format during the interview. Following data collection, all the data were aggregated and then entered in Microsoft Excel. Data analysis was done in the Department of Community Medicine, VSS Medical College, Burla for report generation. Pregnant women, children below 2 years of age and seriously ill persons were excluded from study as per guidelines.

Fig 1: Flowchart for MDA Assessment

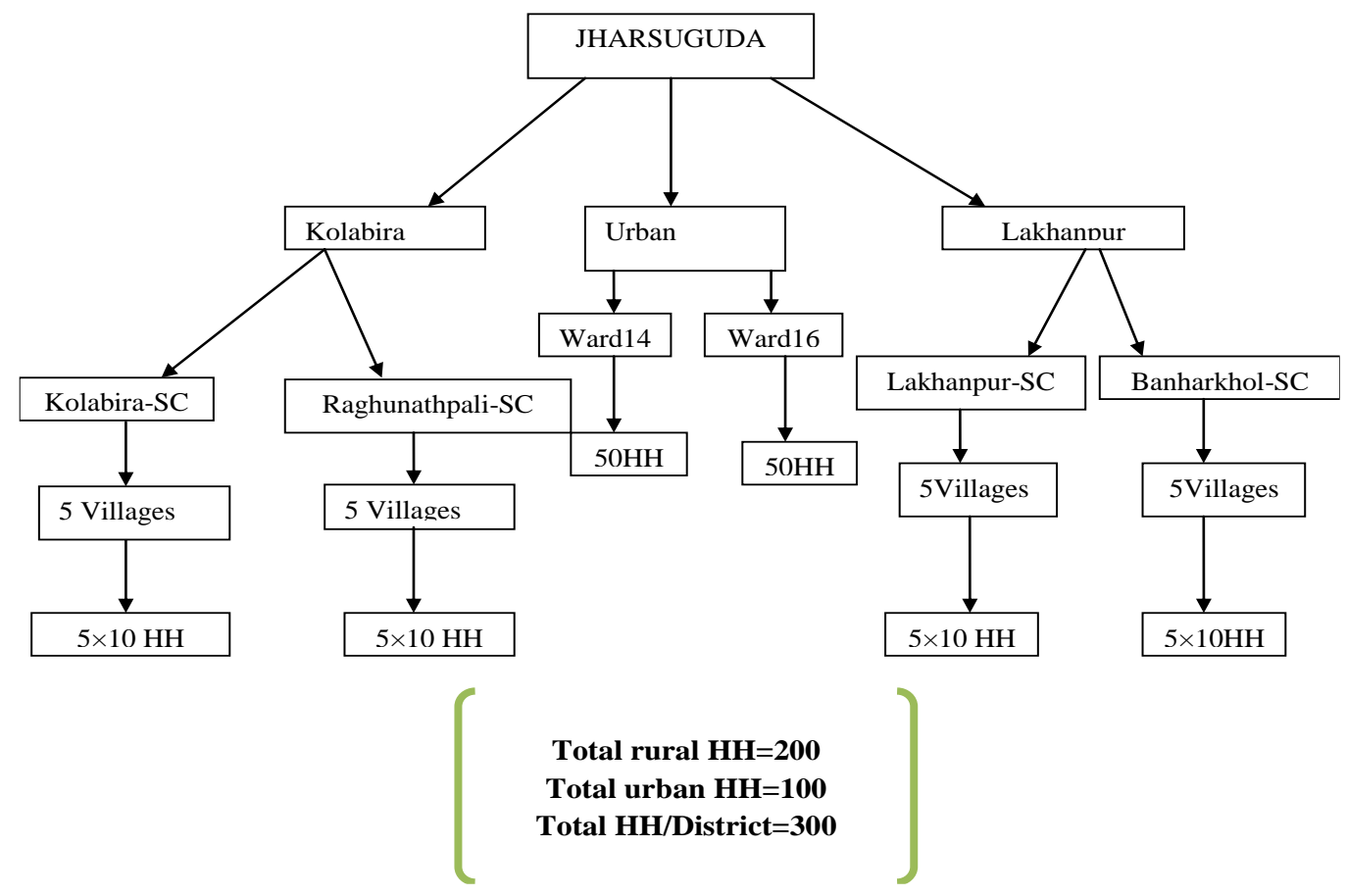


Table 1: Area-wise Age \& Sex distribution ( $N=1537)$

\begin{tabular}{cccccccc}
\hline Age & \multicolumn{5}{c}{ Rural } & \multicolumn{5}{c}{ Urban } & Total \\
\cline { 2 - 6 } & Male & Female & Total & Male & Female & Total & \\
$<15$ & 113 & 107 & 220 & 49 & 58 & 107 & 327 \\
$\begin{array}{c}\text { years } \\
\geq 15\end{array}$ & 446 & 426 & 872 & 144 & 194 & 338 & 1210 \\
$\begin{array}{c}\text { years } \\
\text { Total }\end{array}$ & 559 & 533 & 1092 & 193 & 252 & 445 & 1537 \\
\hline
\end{tabular}

Table 2: Number of beneficiaries who received and consumed drugs in front of Drug Distributors (\%)

\begin{tabular}{|c|c|c|c|c|c|c|c|c|}
\hline \multirow[t]{2}{*}{ Age } & \multicolumn{4}{|c|}{ Rural } & \multicolumn{4}{|c|}{ Urban } \\
\hline & Beneficiaries & Received & Consumed & $\begin{array}{l}\text { Consumed in } \\
\text { front of Drug } \\
\text { Distributor }\end{array}$ & Beneficiaries & Received & Consumed & $\begin{array}{c}\text { Consumed in } \\
\text { front of Drug } \\
\text { Distributor }\end{array}$ \\
\hline$<15$ years & 220 & 214 & 204 & 81 & 107 & 84 & 76 & 2 \\
\hline$\geq 15$ years & 872 & 852 & 836 & 284 & 338 & 288 & 269 & 4 \\
\hline Total & 1092 & $\begin{array}{c}1066 \\
(97.61 \%)\end{array}$ & $\begin{array}{c}1040 \\
(97.56 \%)\end{array}$ & $\begin{array}{c}365 \\
(35.09 \%)\end{array}$ & 445 & $\begin{array}{c}372 \\
(83.59 \%)\end{array}$ & $\begin{array}{c}345 \\
(92.74 \%)\end{array}$ & $\begin{array}{c}6 \\
(1.73 \%)\end{array}$ \\
\hline
\end{tabular}

\section{RESULTS}

The mass drug administration survey for Jharsuguda was carried out in February 2016. The total number of households surveyed was 300. Two blocks viz. Lakhanpur and Kolabira; and urban area of Jharsuguda (Ward no. 14 and 16) were included in the survey. The total number of household members surveyed was 1627 , out of which total number of beneficiaries were 1537 (94.47\%). Of total beneficiaries, 1092 (71.04\%) from rural area and 445 $(28.96 \%)$ belong to urban area. The $5.53 \%$ members not eligible to be beneficiaries included; children $<2$ years age $(45.21 \%)$, pregnant women (12.12\%), and diseased or seriously ill (42.67\%). In Rural areas the number of males and females were more than those in urban areas in both $<15$ years and $\geq 15$ years age group. The no of beneficiaries received and consumed drugs more in rural areas than urban areas in both $<15$ years and $\geq 15$ years age group. In rural areas $97.61 \%$ beneficiaries received drugs compared to $83.59 \%$ in urban areas. Similarly in rural areas $97.56 \%$ consumed drugs as compared to $92.74 \%$ in urban areas.
Around $35.09 \%$ consumed drugs in front of Drug Distributor (DD) in rural areas as compared to $1.73 \%$ in urban areas.

Out of a total 1537 beneficiaries, $6.44 \%$ did not receive drugs. Similarly of the 1438 beneficiaries who received drugs, $3.68 \%$ of beneficiaries did not consume drugs. And $73.21 \%$ of the 1385 beneficiaries who consumed drugs did not consume the drugs in front of the Drug Distributor (DD). The differences in receipt and consumption of drugs in the rural and urban areas was found to be significant $(p<0.05)$ indicating better coverage in the rural area. The most common reason for not consuming drug in rural areas was that the beneficiaries were absent from home (48.4\%) and in urban areas the most common cause was "no information" (33.3\%). Out of 300,35 (11.66 \%) households had no information regarding MDA. AWW were the source of information in $60.33 \%$ of households, followed by ASHA (57\%). Side effects due to drugs were present in $1.05 \%$ of rural beneficiaries and $0.28 \%$ of urban beneficiaries. Most of the side effects were mild and did not require any treatment.

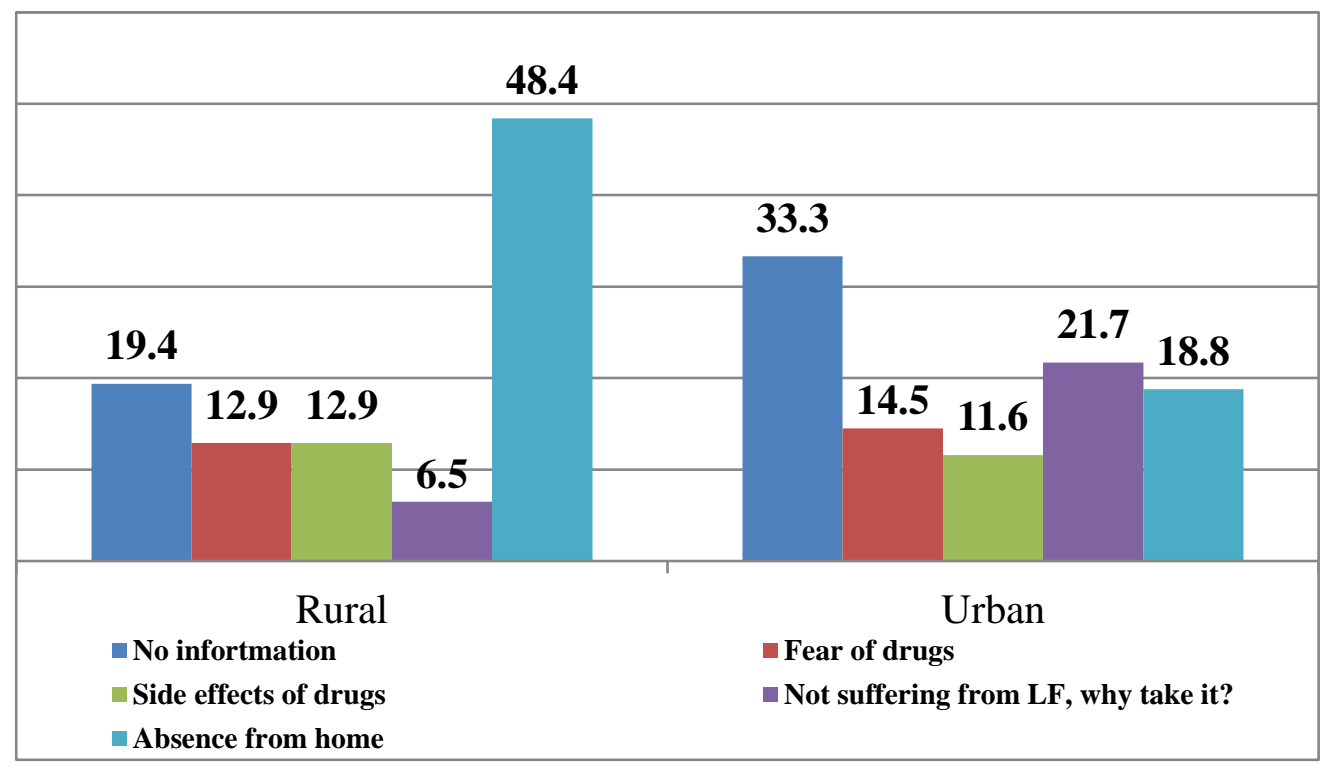

Fig 2: Reasons for not consuming drugs (Figures in \%) 


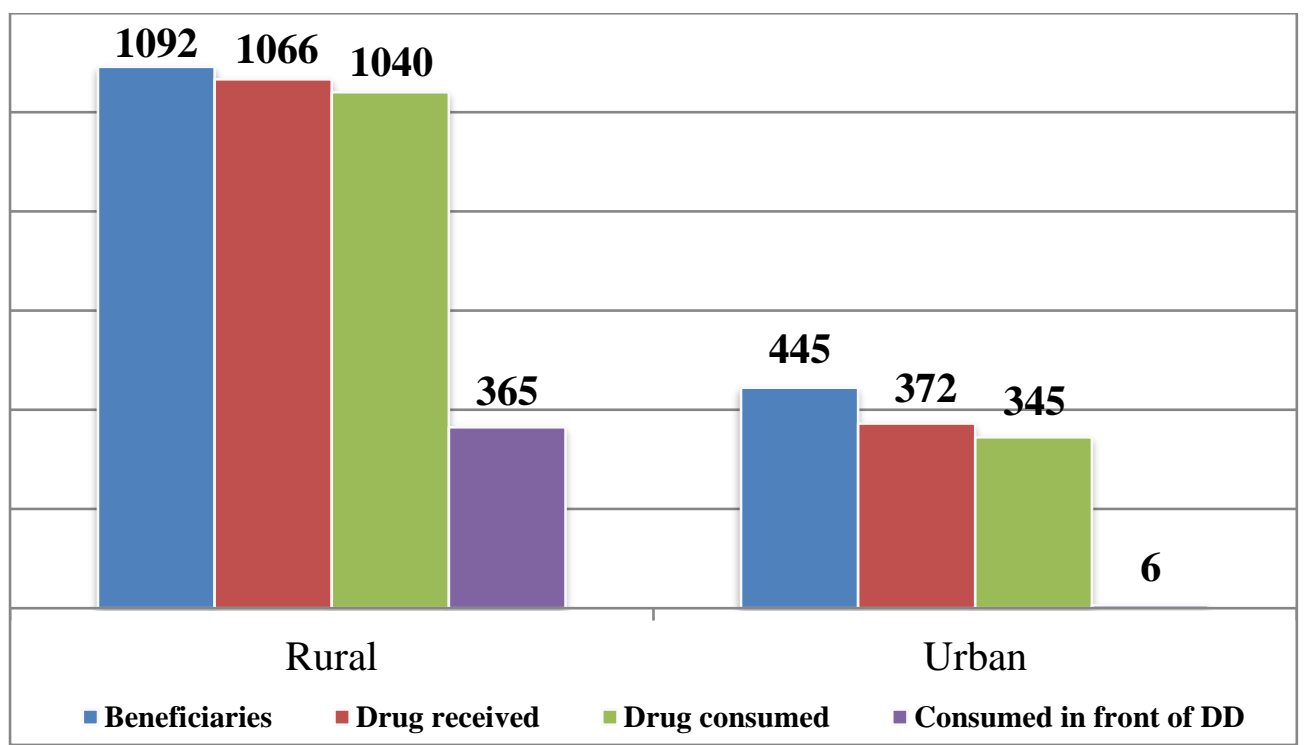

Fig 3: Rural-Urban distribution of beneficiaries (\%)

Table 3: Beneficiaries with Rural-Urban distribution (\%)

\begin{tabular}{|c|c|c|c|c|c|c|c|c|c|}
\hline \multirow[t]{2}{*}{ Residence } & \multicolumn{2}{|c|}{$\begin{array}{l}\text { Drug received } \\
\qquad \mathrm{N}=1537\end{array}$} & \multirow[t]{2}{*}{ Total } & \multicolumn{2}{|c|}{$\begin{array}{l}\text { Drug Consumed } \\
\qquad N=1438\end{array}$} & \multirow[t]{2}{*}{ Total } & \multicolumn{2}{|c|}{$\begin{array}{c}\text { Consumed Drugs In } \\
\text { front Of } D D \\
N=1385\end{array}$} & \multirow[t]{2}{*}{ Total } \\
\hline & Yes & No & & Yes & No & & Yes & No & \\
\hline Rural & $\begin{array}{c}1066 \\
(97.61)\end{array}$ & $\begin{array}{c}26 \\
(2.38)\end{array}$ & $\begin{array}{l}1092 \\
(100)\end{array}$ & $\begin{array}{c}1040 \\
(97.56)\end{array}$ & $\begin{array}{c}26 \\
(2.43)\end{array}$ & $\begin{array}{l}1066 \\
(100)\end{array}$ & $\begin{array}{c}365 \\
(35.09)\end{array}$ & $\begin{array}{c}675 \\
(64.90)\end{array}$ & $\begin{array}{l}1040 \\
(100)\end{array}$ \\
\hline Urban & $\begin{array}{c}372 \\
(83.59)\end{array}$ & $\begin{array}{c}73 \\
(16.40)\end{array}$ & $\begin{array}{c}445 \\
(100)\end{array}$ & $\begin{array}{c}345 \\
(92.74)\end{array}$ & $\begin{array}{c}27 \\
(7.25)\end{array}$ & $\begin{array}{c}372 \\
(100)\end{array}$ & $\begin{array}{c}6 \\
(1.73)\end{array}$ & $\begin{array}{c}339 \\
(98.26)\end{array}$ & $\begin{array}{r}345 \\
(100)\end{array}$ \\
\hline Total & $\begin{array}{c}1438 \\
(93.55)\end{array}$ & $\begin{array}{c}99 \\
(6.44)\end{array}$ & & $\begin{array}{c}1385 \\
(96.31)\end{array}$ & $\begin{array}{c}53 \\
(3.68)\end{array}$ & & $\begin{array}{c}371 \\
(26.78)\end{array}$ & $\begin{array}{c}1014 \\
(73.21)\end{array}$ & \\
\hline
\end{tabular}

Table 4: Source of information $(n=300 \mathrm{HH})(\%)$

\begin{tabular}{lccccc}
\hline Residence & ANM & AWW & ASHA & Radio & TV \\
\hline Rural & 31 & 142 & 108 & 11 & 3 \\
Urban & 2 & 39 & 63 & 2 & 0 \\
Total & 33 & 181 & 171 & 13 & 3 \\
& $(11)$ & $(60.33)$ & $(57)$ & $(4.33)$ & $(1)$ \\
\hline
\end{tabular}

\begin{tabular}{lccc}
\hline \multicolumn{1}{c}{ Table 5: Side effects of MDA (\%) } & Total \\
\hline Side effects & Rural & Urban & 12 \\
\hline Present & 11 & 1 & $(0.86)$ \\
& $(1.05)$ & $(0.28)$ & 1373 \\
Absent & 1029 & 344 & $(99.13)$ \\
& $(98.94)$ & $(99.71)$ & 1385 \\
Total & 1040 & 345 & $(100)$ \\
\hline
\end{tabular}

\section{DISCUSSION}

The assessment of post-MDA activity of Jharsuguda district was carried out by the Department of Community Medicine, VSS Medical College, Burla. In our study, coverage in rural areas was $97.61 \%$ as compared to $83.59 \%$ in urban areas. In study by Kumar et.al the coverage was $85.2 \%$ in Gujarat \& the effective coverage was marginally better in rural areas than urban areas. ${ }^{6}$ In B V Babu study in Orissa, the coverage was $67 \% .^{7}$ The assessed coverage of distribution as per ICMR study was significantly higher in rural areas (65-73\%) of Tamil Nadu compared to urban areas (40-45\%). ${ }^{8}$ In Kerala these figures were
$72-82 \%$ in rural areas and $67-85 \%$ in urban areas respectively. ${ }^{8}$ In a study done in Surat, coverage was slightly better rural than urban. ${ }^{9}$ Karmakar P Ray et al also reported higher coverage and compliance rate $(72.87 \% \& 70.47 \%)$ in rural area as compared to urban areas $(14.22 \% \& 56.25 \%) .{ }^{10}$ According to a study by Nirgude et al in Nalgonda district of Andhra Pradesh found that coverage in rural area was $71.8-96.8 \%$ and $75.9 \%$ in urban area. ${ }^{11}$ The higher coverage in rural areas than urban areas might be due to the fact that the DDs must might be familiar with the people in the rural areas. Persons missed by the team and person not 
available at home were major reasons for non-coverage as the house to house visit by DDs was carried out during the office hours i.e. 9 am to $5 \mathrm{pm}$ so the person might not be at home during this period. While in urban areas there were a proportion of households in spite of being visited were not given drug was negligence on the part of the DDs. In our study the most common reason for noncompliance in rural areas was absent from home (48.4\%) and "no information" (33.3\%) in urban areas. In a study done in Karnataka, $55 \%$ non-compliant population said they were not at home during MDA activity. ${ }^{12}$ In our study $12.9 \%$ in rural \& $11.6 \%$ in urban area did not consume drug due to fear of side effects. In a study done in Karnataka, 19\% did not consume the drug because of fear of side effects. ${ }^{12}$ In a study done in West Bengal, fear of side-effects was the main reason for noncompliance. ${ }^{13}$

\section{CONCLUSION AND RECOMMENDATIONS}

The coverage in rural areas is more than urban areas. This requires the use of mass media such as local TV channels, newspapers, posters and banners at public places for increasing the awareness and coverage of MDA in the urban areas. Consumption of drugs in front of drug distributor is very low. The local health authorities should emphasize on the grass root level health providers for ensuring the consumption of MDA drugs in front of the drug distributors. This will not only increase the confidence among the community regarding intake of MDA drugs but also ensure a better coverage. Supervision of MDA activities by the local health authorities is essential to allay the fears of side effects of MDA drugs by the community thereby enhancing the coverage of MDA.

\section{REFERENCES}

1. Filariasis Control in India \& Its Elimination, Guidelines on Elimination of Lymphatic Filariasis India. [accessed on 2016 Mar 30]. Available from [www.nvbdcp.gov.in/doc/guidelines-filariasiselimination-india.pdf.]

2. Global Programme to Eliminate Lymphatic Filariasis progress report 2000-2009 and strategic plan 20102020.(WHO/HTM/NTD/PCT/2010.6). Geneva, World Health Organization, 2010. [Accessed on 2016 Apr 2] Available from [whqlibdoc.who.int/publications/2010/9789241500722_eng.pdf]

3. Govt. of India (2014), Annual Report 2013-2014, Ministry of Health and Family Welfare, New Delhi. [Available from: http://www.mohfw.nic.in/WriteReadData//892s/565878963254123 6.pdf] [Accessed on 2016 Apr 2]

4. K. Park, Park's Text book of Preventive and Social Medicine. 23rd edition. India: Bhanot; 2015.

5. Hussain et al. Mass drug administration for lymphatic filariasis elimination in a coastal state of India: a study on barriers to coverage and compliance. Infectious Diseases of Poverty 2014; 3:31.

6. Kumar $\mathrm{P}$ et.al; Evaluation of MDA 2006 in Gujarat.I J.C.M Vol.33 No 1, January 2008, 38-42.

7. B V Babu \& S K Kar MDA against filariasis in Orissa. Tropical Medicine \& international Health.Vol 9 .No 06, page 702-709. June 2004.

8. ICMR. Prospects of eliminating lymphatic filariasis in India. ICMR Bulletin 2002; 32: 1-14. [Accessed on 2016 Apr 3]. Available from [http://icmr.nic.in/bumayjun02.pdf]

9. Mehta S, Shah V, Verma A, Patel NB, Bansal RK. Comparison of Coverage and Compliance of Mass Drug Administration 2012 in Surat, India. Natl J Community Med 2012; 3(3):468-72.

10. Karamkar P Ray, K Mitra, Chatterjee Anirban, PK jana, Bhattacharya S, Lahiri SK. A study on coverage, compliance and awareness about Mass Drug Administration for elimination of lymphatic filariasis in a district of West Bengal, India. J Vector Borne Dis 2011;48:101-4

11. Nirgude Abhay S., Naik Poonam R., Kondagunta Nagaraj, Reshmi Sidramappa S., Takalkar Anant A., Prasad VG. Evaluation of coverage and compliance of Mass Drug Administration Programme 2011 for elimination of lymphatic filariasis in Nalgonda district of Andhra Pradesh, INDIA, National Journal of Community Medicine vol 3 issue 2 April June 2012; $p$. 288-293

12. TS Ranganath, N Ramakrishna Reddy. Elimination of Lymphatic Filariasis: Mass Drug Administration in Endemic Areas of (Bidar District) Karnataka-2008. Indian J Community Medicine: 2012 : 37(4):219-222

13. Santanu Ghosh, Amrita Samanta, and Seshadri Kole. Mass drug administration for elimination of lymphatic filariasis: Recent experiences from a district of West Bengal, India Trop Parasitol. 2013 Jan-Jun; 3(1): 67-71

\section{Source of Support: Nil. Conflict of Interest: None Declared.}

Copyright: (c) the author(s) and publisher. IJMRP is an official publication of $\mathrm{lbn}$ Sina Academy of Medieval Medicine \& Sciences, registered in 2001 under Indian Trusts Act, 1882.

This is an open access article distributed under the terms of the Creative Commons Attribution Non-commercial License, which permits unrestricted non-commercial use, distribution, and reproduction in any medium, provided the original work is properly cited.

Cite this article as: Durga Madhab Satapathy, Subrat Kumar Pradhan, Himanshu Prasad Acharya, Udayan Nayak, Sandeep Kumar Agrawal, Gitismita Naik, Upasana Sinha. Rural and Urban Differences in MDA Coverage for Filariasis in Jharsuguda District of Odisha. Int J Med Res Prof. 2016; 2(5):70-74. 